\title{
ORIGINAL ARTICLE \\ SCIPA Com: outcomes from the spinal cord injury and physical activity in the community intervention
}

\author{
BIR de Oliveira ${ }^{1}$, EK Howie ${ }^{1}$, SA Dunlop ${ }^{2}$, MP Galea ${ }^{3}$, A McManus $^{4}$ and GT Allison ${ }^{1}$
}

Study design: Quasi-experimental translational study with pre- and post-measures.

Objectives: To determine the effects of the Spinal Cord Injury and Physical Activity in the Community (SCIPA Com) intervention on leisure-time physical activity (LTPA) and associated outcomes among participants with spinal cord injury (SCI).

Setting: Young Men's Christian Associations and community fitness centers, Australia and New Zealand.

Methods: SCIPA Com consisted of three stages: (i) training exercise professionals via the Train the Trainers Spinal Cord Injury course; (ii) implementation of supervised physical activity programs twice a week for 30 to $60 \mathrm{~min}$ for 8 to 12 weeks; and (iii) follow-up assessments on health outcomes over 9 months. Participants with SCI were classified as active or inactive by baseline LTPA levels and linear mixed methods compared LTPA between groups over time.

Results: Sixty-four community-dwelling participants with $\mathrm{SCl}$ completed customized physical activity programs. Compared with baseline, there were significant improvements in LTPA (26 min per day, 95\% confidence interval (CI): 16.6-35.4; $P<0.001$ ), functional goals $(2,95 \% \mathrm{Cl}: 1.72-2.37 ; P<0.001)$, self-esteem $(1.5,95 \% \mathrm{Cl}: 0.72-2.27 ; P<0.001)$ and overall quality of life $(P<0.05)$. Over time, LTPA participation was greater among the active compared with the inactive group, although LTPA levels among the inactive improved compared with baseline.

Conclusions: Significant improvements in LTPA participation and health outcomes were observed, especially among inactive individuals with SCI. SCIPA Com is an ecologically valid intervention based on training and support provided to community exercise professionals who, although new to adapted training, delivered effective physical activity programs for those at risk of inactivity.

Sponsorship: Transport Accident Commission (Project Number DP172) and the International Postgraduate Research Scholarship (IPRS), Curtin University.

Spinal Cord (2016) 54, 855-860; doi:10.1038/sc.2015.235; published online 19 January 2016

\section{INTRODUCTION}

A systematic review of literature has established that structured leisure-time physical activity (LTPA) is associated with better health and fitness among individuals with spinal cord injury (SCI). ${ }^{1}$ Accordingly, physical activity is highly recommended for the prevention of secondary problems, as well as the enhancement of functional abilities, psychological well-being and community integration post discharge from rehabilitation services. ${ }^{1-4}$

Active lifestyles among the SCI population have been facilitated through referral systems from rehabilitation services to the community setting, ${ }^{3}$ increased community involvement ${ }^{5}$ and customized physical activity programs. ${ }^{6,7}$ Additional studies ${ }^{8,9}$ revealed benefits from interventions in community-based facilities, which reduced associated costs and transportation times.

Nevertheless, inactivity levels in the SCI population are alarmingly high. ${ }^{10}$ Few studies have engaged the community or addressed barriers regarding accessibility, affordability and professional assistance. ${ }^{11}$ Despite the known importance of community support, health education, multi-site and multi-faceted interventions, ${ }^{12}$ no studies have combined these components to increase physical activity in people with SCI.

The Spinal Cord Injury and Physical Activity in the Community (SCIPA Com) intervention is an original initiative designed by the authors of this study to fulfill the demand for physical activity community services for people with SCI. A companion paper (that is, Perceived barriers and facilitators to physical activity before and after SCIPA Com) describes the development of SCIPA Com and the procedures required to transition individuals with SCI from institutionalized health care to a sustainable model of community health promotion and integration.

Three questions guided this research: Do structured physical activity interventions in the community increase LTPA levels, functional goal satisfaction, self-esteem and quality of life of people with SCI? Are the outcomes different for sub-cohorts that are classified as active or inactive at baseline? Do individuals with SCI adhere to physical activity in the longer term? The hypothesis is that a model of health promotion in community fitness centers can lead to improved LTPA levels and health in individuals with SCI over time.

${ }^{1}$ School of Physiotherapy and Exercise Science, Faculty of Health Sciences, Curtin University, Bentley, Western Australia, Australia; ${ }^{2}$ Department of Experimental and Regenerative Neurosciences, School of Animal Biology, University of Western Australia, Crawley, Western Australia, Australia; ${ }^{3}$ Department of Medicine (Royal Melbourne Hospital), The University of Melbourne, Parkville, Victoria, Australia and ${ }^{4}$ Centre of Excellence for Science, Seafood and Health, Curtin University, Bentley, Western Australia, Australia

Correspondence: Dr BIR de Oliveira, Curtin University, School of Physiotherapy and Exercise Sciences, Kent Street, Bentley, 6102 Western Australia, Australia.

E-mail: Beatriz.Oliveira@curtin.edu.au

Received 3 September 2015; revised 1 December 2015; accepted 8 December 2015; published online 19 January 2016 


\section{Design}

This was a quasi-experimental translational study with pre- and postassessments. We evaluated physical activity programs for people with SCI living in the community, which were delivered locally by community service providers. A control group involving no intervention was discounted because of the lack of interest and unethical withholding of physical activity and associated benefits. ${ }^{1}$ Results were used to determine the effectiveness of the SCIPA Com intervention in several sites and in a large SCI population.

\section{Participants}

Recruitment was conducted between November 2011 and November 2013 in the Australian states of Western Australia, Victoria and Queensland, as well as one city in New Zealand (Christchurch). People with SCI were informed of the study via online newsletters from SCI organizations, referrals from health providers and using a snowball sampling method.

Participants were between 18 and 80 years of age, diagnosed with a complete or an incomplete SCI for 1 year or longer, with self-reported SCI classified as C5 to S4-5, having AIS (American Spinal Injury Association (ASIA) Impairment Scale) score A to C, with intact cognitive function, living in the community and medically approved to engage in physical activity. Subjects were excluded in cases of full recovery of movement and function post injury or if unable to perform physical activity in a fitness center due to medical contraindications or a self-reported SCI classified as AIS A-C4 or above. ${ }^{13}$

Exercise professionals required accreditation in fitness training with their country's professional registration boards, Certificate levels 3 or 4 in fitness training or a university degree in health sciences, a minimum of 1-year work experience in the fitness industry and approval from their center manager to deliver SCIPA Com.

\section{MATERIALS AND METHODS}

The SCIPA Com intervention is described in Supplementary Appendix (SCIPA Com: A Model of Health Promotion and Community Integration). In summary, implementation of SCIPA Com in fitness centers involved three stages: (i) training exercise professionals on safety and adapted physical activity for people with SCI through 'Train the Trainers Spinal Cord Injury (T3-SCI)' course; (ii) delivery of customized physical activity intervention for clients with SCI based on their goals, physical strengths and personality attributes; ${ }^{6}$ and (iii) baseline and three follow-up assessments over 9 months.

This study was approved by Curtin University Human Research Ethics Committee (HR80/2010) and the Health and Disability Ethics Committees in New Zealand (13/STH/36). We certify that all applicable institutional and governmental regulations concerning the ethical use of human volunteers were followed during the course of this research.

\section{Stage 1}

SCI organizations were contacted to determine the feasibility of SCIPA Com. Center managers of Young Men's Christian Associations and community fitness centers run by Local Councils were approached to offer exercise professionals the 'T3-SCI' course free of charge. This course was developed by experienced physical therapists, academics and stakeholders (that is, people with SCI) and accredited by national health and fitness industry associations of Australia (Fitness Australia) and New Zealand (Registry of Exercise Professionals). Exercise professionals were required to complete $10 \mathrm{~h}$ of guided training. They received ongoing support from physical therapists and were provided with Supplementary Materials and methods with emphasis on risk management and safety in the event of an emergency.

A SCIPA Com liaison officer referred participants with SCI to their nearest accessible fitness center, negotiated terms with gym managers and organized payments of monthly gym memberships, which ranged from $\$ 20$ to $\$ 130$ USD. Most exercise professionals agreed to participate in
SCIPA Com without an honorarium, although those who earned income exclusively on the basis of personal training fees were compensated \$20 to \$25 USD per session.

\section{Stage 2}

Standard clinical questionnaires with documented construct validity and intra- and inter-rater reliability were used to measure four outcomes in participants with SCI: LTPA levels (via the 'Physical Activity Recall Assessment for Individuals with SCI (PARA-SCI)'), ${ }^{14}$ functional goal achievement (with the 'Patient-Specific Functional Scale (SFS)'), ${ }^{15}$ self-esteem (using the 'Rosenberg Self-Esteem Scale (RSS)') ${ }^{16}$ and quality of life (through the 'World Health Organization Quality of Life Scale - BREF (WHOQOL-BREF)'). ${ }^{17}$

PARA-SCI estimates the total time in minutes performing self-reported mild, moderate and heavy intensity LTPA in the three previous days, leading to the assessment date. ${ }^{14}$ Goal-setting was recorded via PSFS scores of three or more nominated activities on a 10-point numeric rating scale. ${ }^{15}$ Ten statements on the RSS are rated on a 4-point scale, with a total score below 15 suggesting low self-esteem. ${ }^{16}$ A 5-point Likert-scale was used in the WHOQOL-BREF to measure 26 attributes of quality of life. ${ }^{17}$

Baseline PARA-SCI results were used to stratify participants into the inactive group (performing $\leqslant 150 \mathrm{~min}$ of moderate-intensity or $60 \mathrm{~min}$ of vigorous-intensity LTPA per week) or the active group (performing $\geqslant 150 \mathrm{~min}$ of moderate-intensity or $60 \mathrm{~min}$ of vigorous-intensity LTPA per week). ${ }^{18}$ Exercise professionals guided clients with SCI on physical activity participation for 30 to 60 min twice a week through individual or group sessions (with a maximum of three participants per exercise professional) at their discretion. The intervention was based on evidenceinformed physical activity guidelines developed for adults with SCI. ${ }^{19}$ It included moderate-intensity endurance and strength training with progressive increments as tolerated, as well as flexibility, balance and proprioceptive activities. Exercise professionals were instructed to supervise the intervention at all times, proceed with caution and record any adverse events.

\section{Stage 3}

Assessments were carried out by two trained researchers in person or via telephone calls and required $1-2 \mathrm{~h}$ to complete. In addition to baseline measures, participants were assessed on three other occasions: 3 months (immediately after intervention), 6 months and 9 months. During follow-up assessments, participants were informed on their progress and encouraged to remain active by independently progressing their physical activity program or partaking in alternative activities of their interest. Several fitness centers that participated in SCIPA Com also offered discounted membership fees to enable participants' continuous access to facilities post intervention.

\section{Statistical analysis}

Descriptive statistics of participants at baseline and outcome measures over four assessment periods were calculated using STATA/IC 13.1 for Windows (StataCorp LP, College Station, TX, USA). Independent samples $t$-tests, Mann-Whitney $U$-tests and $\chi^{2}$ tests were applied to compare baseline differences between the active and the inactive groups.

The distribution of variables was analyzed through normality statistics (skewness and kurtosis), histograms and boxplots. Standard errors were bootstrapped using 1000 replications to account for slight deviations from normal distribution. Participants involved in at least baseline and 3-month follow-up assessments were included in the statistical models.

Separate linear mixed models were used to compare LTPA levels, functional goal achievement, self-esteem and quality of life scores between assessments periods. Individuals were included as a random intercept to account for repeated measurements.

Linear contrasts were used to compare the estimated means against baseline values. Interactions between active/inactive groups and time were tested in the model. Results are reported as estimated mean differences, 95\% confidence intervals and probability values (with statistical significance set at $P<0.05$ ). 


\section{RESULTS}

From a total of 39 community fitness centers contacted, 32 undertook training in SCIPA Com. In Stage 1, the 'T3-SCI' course attracted interest of 95 exercise professionals. Just over half completed the training $(n=50)$. From this pool of exercise professionals, 32 were sought by one or more clients with SCI. Figure 1 displays participation numbers among individuals with SCI throughout Stages 2 to 3 .

Sixty-four participants with SCI completed the intervention and provided data for preliminary statistical analysis. Their demographic characteristics are presented in Table 1 . The average age, proportion of causes of SCI and motor level of the participants are similar to those reported in a 2009 epidemiological study involving Australians with SCI. ${ }^{20}$ Male SCIPA Com participants were over five times more likely to be active compared with females at baseline $(P<0.001)$, and the active group had a fivefold chance of having a traumatic SCI compared with the inactive group $(P<0.001)$.

Response rates reduced to $95.3 \%$ at 6-month follow-up assessments. The final follow-up period was censured because of project time constraints, finalizing assessments with 40 subjects.

Total group increases in LTPA were significant in all assessment periods compared with baseline as shown in Table 2. LTPA was highest at the end of the intervention ( 3 months). Although LTPA decreased after 6 and 9 months, they remained statistically higher

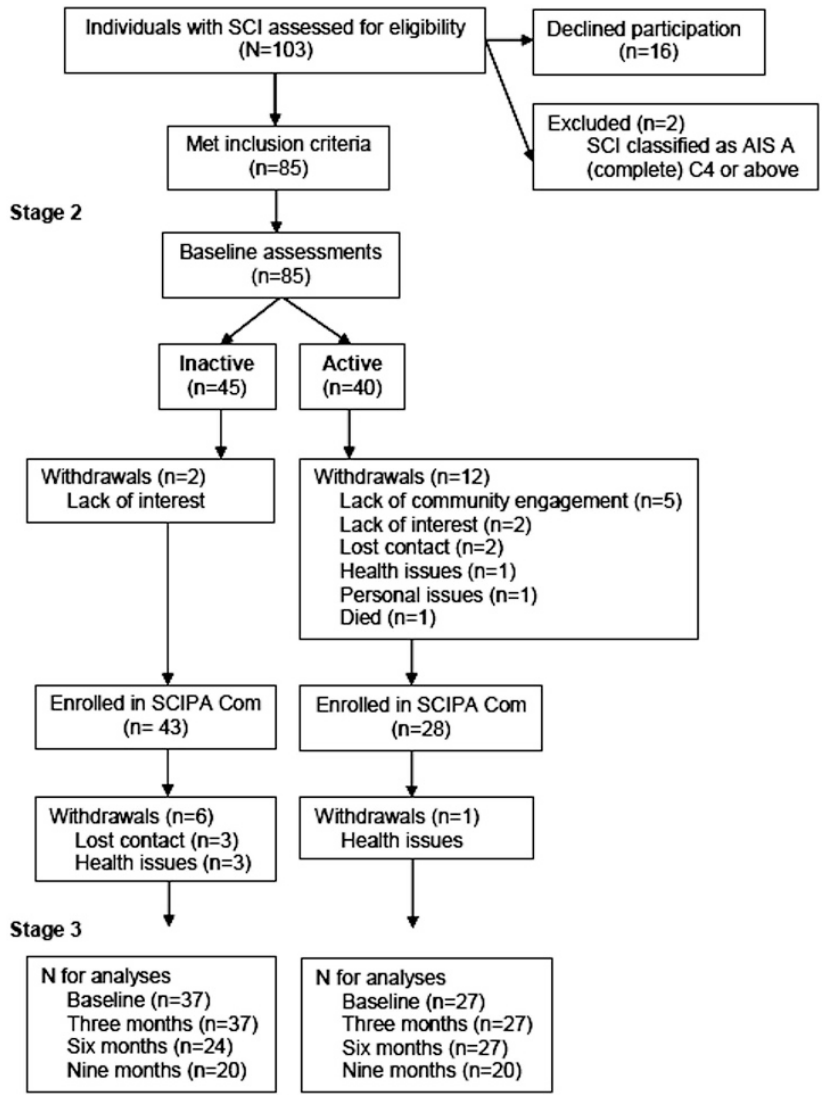

Figure 1 Flow chart of participants in the Spinal Cord Injury and Physical Activity in the Community intervention. The numbers for the nine months follow-up were date censored due to the study's end prior to the nine months follow-up period. Only 40 participants were contacted for the last assessment. ASIA Impairment Scale (AIS), American Spinal Injury Association $(\mathrm{ASI} A)$ and spinal cord injury $(\mathrm{SCI})$. compared with baseline and above levels recommended in physical activity guidelines ${ }^{18,19}$ thereby showing adequate maintenance effects after 3 months. Only one adverse event was reported for a participant who had a shoulder re-injury due to excessive weight training in week 11 .

Greater improvements were observed in the inactive cohort compared with the active population, who maintained appropriate LTPA levels over time as shown in Figure 2.

Total group and separate group analysis indicated significant improvements in secondary health outcomes over most follow-up periods, as presented in Tables 3 and 4. Subgroup analysis revealed that the percentage of individuals in the active group who maintained LTPA levels above the threshold was $100 \%(n=27)$ at 3 months, $89 \%$ $(n=24)$ at 6 months and $93 \%(n=25)$ at 9 months. A reduced proportion of people in the inactive group displayed LTPA levels above the threshold at $3(76 \%, n=28), 6(47 \%, n=17)$ and 9 months $(50 \%, n=19)$.

\section{DISCUSSION}

SCIPA Com is the first intervention to engage community-based fitness centers (for example, Young Men's Christian Associations) and exercise professionals readily available in a variety of locations, as opposed to hospitals and university facilities or home-based interventions. ${ }^{8,9}$ In agreement with other studies, interventions delivered by exercise professionals via SCIPA Com showed increased physical activity uptake and reduced expenses, while making these services available to others in the community. ${ }^{8,21}$ The 'T3-SCI' course also provided exercise professionals with an opportunity to adapt their

Table 1 Baseline characteristics of participants with spinal cord injury

\begin{tabular}{|c|c|c|c|c|}
\hline & $\begin{array}{l}\text { Total } \\
N=64\end{array}$ & $\begin{array}{l}\text { Inactive } \\
n=37\end{array}$ & $\begin{array}{l}\text { Active } \\
n=27\end{array}$ & P-value \\
\hline \multicolumn{5}{|l|}{ Gender (\%) } \\
\hline Male & 72 & 59 & 89 & 0.01 \\
\hline Female & 28 & 41 & 11 & \\
\hline Age (years) & $48.6 \pm 13$ & $48.9 \pm 12.5$ & $48.2 \pm 14.6$ & 0.826 \\
\hline Body weight (kg) & $80.7 \pm 19.7$ & $82 \pm 23.2$ & $79 \pm 14$ & 0.563 \\
\hline \multicolumn{5}{|l|}{ Cause (\%) } \\
\hline Traumatic & 81 & 73 & 93 & 0.047 \\
\hline Non-traumatic & 19 & 27 & 7 & \\
\hline \multicolumn{5}{|c|}{ Motor level, ASIA impairment scale (\%) } \\
\hline $\mathrm{C} 5-\mathrm{C} 8, \mathrm{~A}$ & 17 & 21.5 & 11 & 0.481 \\
\hline $\mathrm{C} 5-\mathrm{C} 8, \mathrm{~B}$ or $\mathrm{C}$ & 30 & 30 & 30 & \\
\hline T1-S4 to S5, A & 28 & 21.5 & 37 & \\
\hline T1-S4 to S5, B or C & 25 & 27 & 22 & \\
\hline Time (years) since injury & $9(2-21)$ & $9(2-19)$ & $10(4-26)$ & 0.342 \\
\hline \multicolumn{5}{|l|}{ Assistive device (\%) } \\
\hline Manual wheelchair & 76 & 73 & 82 & 0.113 \\
\hline Electric wheelchair & 11 & 19 & 0 & \\
\hline Crutches, cane & 8 & 5 & 11 & \\
\hline None & 5 & 3 & 7 & \\
\hline LTPA levels (min per day) & $19(0-60)$ & $0(0-10)$ & $60(48-80)$ & $0.001^{a}$ \\
\hline
\end{tabular}


Table 2 Medium and heavy LTPA during baseline compared with follow-up periods

\begin{tabular}{|c|c|c|c|c|c|c|c|c|c|}
\hline \multirow{2}{*}{$\begin{array}{l}\text { LTPA } \\
\text { (min per day) }\end{array}$} & \multicolumn{3}{|c|}{ Total $N=64$} & \multicolumn{3}{|c|}{ Inactive $(n=37)$} & \multicolumn{3}{|c|}{ Active $(n=27)$} \\
\hline & Median (IQR) & $\begin{array}{l}\text { Score difference } \\
(95 \% \mathrm{Cl})\end{array}$ & P-value & Median (IQR) & $\begin{array}{c}\text { Score difference } \\
(95 \% \mathrm{Cl})\end{array}$ & P-value & Median (IQR) & $\begin{array}{c}\text { Score difference } \\
(95 \% \mathrm{Cl})\end{array}$ & P-value \\
\hline Baseline & $19.8(0-60)$ & & & $0(0$ to 10$)$ & & & 60 (48 to 80 ) & & \\
\hline 3 months & $60(32.5-70)^{*}$ & $26.0(16.6-35.4)$ & $<0.001^{*}$ & $45(30-60)^{*}$ & $41.9(33.7-50.1)$ & $<0.001^{*}$ & $62.6(56.6-90)$ & $4.3(-10.9,19.6)$ & 0.579 \\
\hline 6 months & $40(21.6-65)^{*}$ & $15.2(5.8-24.6)$ & $<0.001^{*}$ & $26.6(0-55.6)^{*}$ & 31 (21.8-40.2) & $<0.001^{*}$ & $53.3(40-81.6)$ & $-6.5(-21.8,8.7)$ & 0.400 \\
\hline
\end{tabular}

Abbreviations: $\mathrm{Cl}$, confidence interval; IQR, interquartile range; LTPA, leisure-time physical activity.

IQR Q1 to Q3 of LTPA in min per day. Score difference compared with baseline and $95 \% \mathrm{Cl}$. ${ }^{*} P<0.001$.

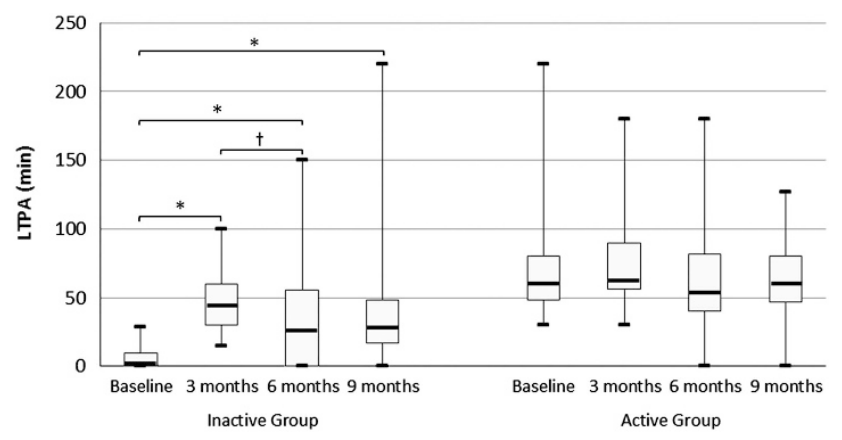

Figure 2 Changes in leisure-time physical activity (LTPA) levels in minutes (min) per day over four assessment periods in the inactive $(n=37)$ and active groups $(n=27)$. Values expressed as median (bold horizontal line), interquartile range (boxes), minimum and maximum values (whiskers). ${ }^{*} \mathrm{p}<.001$ (significant increase in LTPA); $\nmid p<.05$ (significant reduction in LTPA).

knowledge in health and fitness for clients with SCI. Their lack of experience with people with disabilities did not deter development of effective programs.

Our hypothesis was supported by the fact that, regardless of baseline differences, at the conclusion of SCIPA Com, subjects reported an average of $60 \mathrm{~min}$ of moderate-to-heavy LTPA per day. This value surpassed the daily recommended LTPA levels ( $20 \mathrm{~min}$ per day of moderate-to-heavy LTPA) ${ }^{19}$ and standards set by the American College of Sports Medicine. ${ }^{18}$ The average improvement was remarkably higher in this study compared with similar programs that resulted in improvements between 17 and 155 min of LTPA per week. ${ }^{8,9}$ This difference was possibly due to the alignment of exercise programs with the patient's expectations and capabilities.

Reported increases in LTPA among SCIPA Com participants were accompanied by improvements in functional satisfaction and quality of life. Initial comparisons between the active and inactive groups in SCIPA Com had already indicated better quality of life among the active group, as did a cross-sectional study involving 264 individuals with chronic SCI. ${ }^{4}$ Physical activity is known to enhance psychological well-being and self-efficacy, ${ }^{2}$ which may have been reflected in improved functional satisfaction scores.

van Leeuwen $e t$. al. $^{2}$ observed a moderate association $(r=0.23-0.62)$ between quality of life and self-esteem, which partially explains improved self-esteem measures obtained in this study. Nevertheless, our study was the first to analyze improvements in self-esteem in people with SCI within the context of a physical activity program, and further investigations are warranted.
The number of people with SCI across different states in Australia and in New Zealand interested in participating in SCIPA Com revealed an important and an unmet demand for physical activity opportunities in community-based facilities after discharge from rehabilitation services. Previous studies reinforce this demand with reported high attendance rates in health promotion initiatives, hosting between 140 health professionals ${ }^{5}$ and 135 wheelchair users. $^{8}$

However, the large number of exercise professionals who did not follow through with 'T3-SCI' indicated difficulties in their engagement. Exercise professionals had the autonomy to complete the online course at their convenience, which was a different approach from that adopted by 'SCI Action Canada' and 'SCI Ontario' events. ${ }^{5}$ These events presented an established time frame with the participation of a larger cohort in the community, which could be better incentives to increased participation.

Finally, our findings are consistent with studies that revealed the influence of gender and lesion characteristics on physical activity behavior. ${ }^{22}$ Men with SCI are believed to be more active because of gender role activities (such as physical tasks), having greater interest in sports, being more competitive/risk-taking and receiving better social support to engage in physical activity compared with women. ${ }^{22}$ Having extroverted traits may have also increased the risk of traumatic SCI. $^{23}$

\section{CONCLUSIONS}

SCIPA Com is an ecologically valid intervention for those at risk of inactivity. It is based on training and support provided to community exercise professionals who, although new to adapted training, delivered effective physical activity interventions. Previously inactive individuals with SCI significantly improved LTPA participation, quality of life, self-esteem and functional achievements. Results indicate that rehabilitation professionals and liaison officers should emphasize risk management and safety procedures during the training of exercise professionals. At the same time, people with SCI need to be involved in community physical activity programs post discharge from rehabilitation services.

\section{Future research}

Assistance for those who did not adhere to physical activity in the later stages is still warranted. Factors associated with inactivity among women and difficulties with community engagement need to be addressed in prospective studies. An economics analysis is also necessary to determine the sustainability of SCIPA Com over time. 
Table 3 Secondary health outcomes scores during baseline compared with follow-up periods in the total group

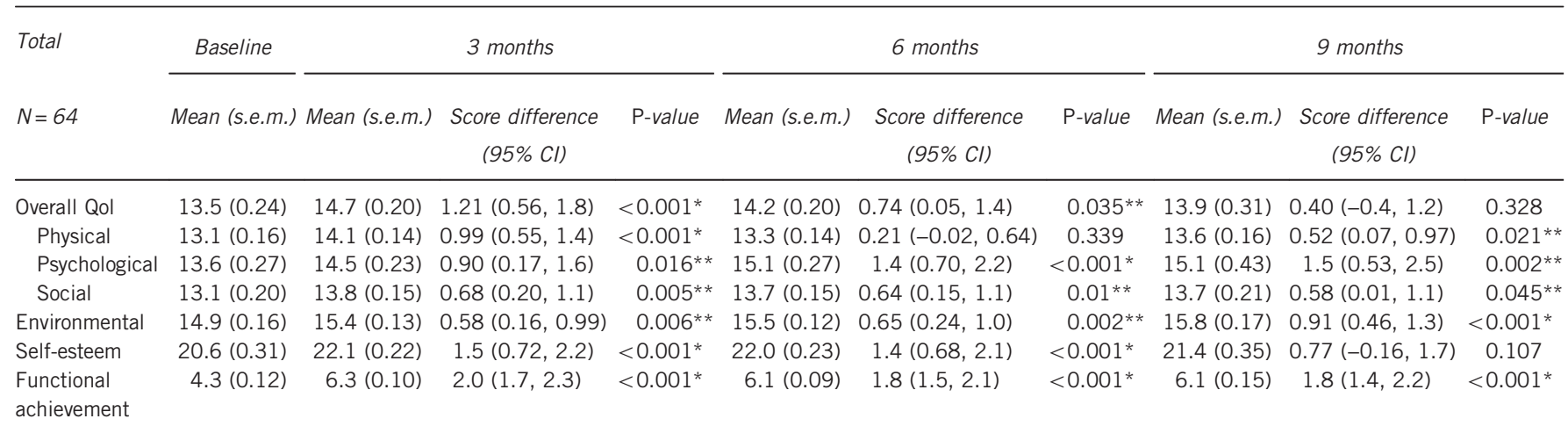

Abbreviations: $\mathrm{Cl}$, confidence interval; QoL, quality of life.

Mean and s.e.m. of scores over time; score difference compared with baseline and $95 \% \mathrm{Cl}$. ${ }^{*} P<0.001$ and ${ }^{* *} P<0.05$ indicate significant differences between estimated means at baseline compared with follow-up periods using separate linear mixed models.

Table 4 Secondary health outcomes scores during baseline compared with follow-up periods in the inactive and active groups

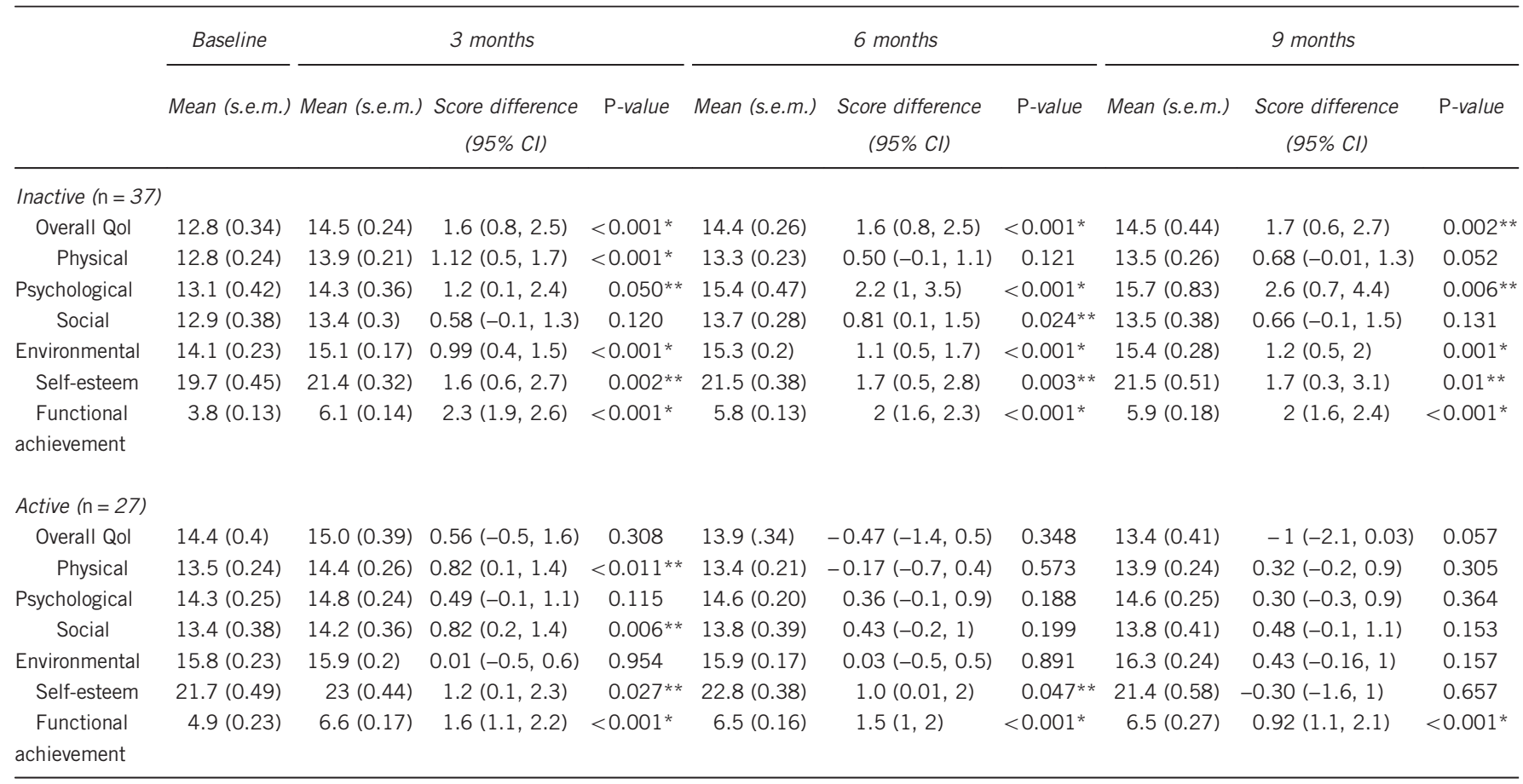

Abbreviations: $\mathrm{Cl}$, confidence interval; QoL, quality of life.

Mean and s.e.m. of scores over time; score difference compared with baseline and $95 \% \mathrm{Cl}$. ${ }^{*} P<0.001$ and ${ }^{* *} P<0.05$ indicate significant differences between estimated means at baseline compared with follow-up periods using separate linear mixed models.

\section{DATA ARCHIVING}

There were no data to deposit.

\section{CONFLICT OF INTEREST}

The authors declare no conflict of interest.

\section{ACKNOWLEDGEMENTS}

This study was largely funded by the Transport Accident Commission of the State of Victoria and Curtin University, Australia. We received their unconditional support, and they had no influence on the analysis of results. BIRdeO received support through the International Postgraduate Research Scholarship provided by Curtin University. We thank and acknowledge the assistance received from members of the SCIPA group, participants in this study, the YMCA, participating council fitness centers and SCI organizations.
1 Hicks AL, Martin Ginis KA, Pelletier CA, Ditor DS, Foulon B, Wolfe DL. The effects of exercise training on physical capacity, strength, body composition and functional performance among adults with spinal cord injury: a systematic review. Spinal Cord 2011; 49: 1103-1127.

2 van Leeuwen CMC, Kraaijeveld S, Lindeman E, Post MWM. Associations between psychological factors and quality of life ratings in persons with spinal cord injury: a systematic review. Spinal Cord 2012; 50: 174-187.

3 Rimmer JH, Henley KY. Building the crossroad between inpatient/outpatient rehabilitation and lifelong community-based fitness for people with neurologic disability. JNPT 2013; 37: 72-77.

4 Anneken V, Hanssen-Doose A, Hirschfeld S, Scheuer T, Thietje R. Influence of physical exercise on quality of life in individuals with spinal cord injury. Spinal Cord 2010; 48 . 393-399.

5 Gainforth HL, Latimer-Cheung AE, Athanasopoulos P, Martin Ginis KA. Examining the feasibility and affectiveness of a community-based organization implementing an eventbased knowledge mobilization initiative to promote physical activity guidelines for people with spinal cord injury among support personnel. Health Promot Pract 2014; 16: $55-62$. 
6 Park N, Peterson C. Character strengths: research and practice. J Coll Character 2009; 10: $1-10$.

7 Elley CR, Dean S, Kerse N. Physical activity promotion in general practice: patient attitudes. Aust Fam Physician 2007; 36: 1061-1064.

8 Froehlich-Grobe K, Lee J, Aaronson L, Nary DE, Washburn RA, Little TD. Exercise for everyone: a randomized controlled trial of project workout on wheels in promoting exercise among wheelchair users. Arch Phys Med Rehabil 2014; 95: 20-28.

9 Wise H, Jackson Thomas K, Nietert P, Brown D, Sword D, Diehl N. Home physical activity programs for the promotion of health and wellness in individuals with spinal cord injury. Top Spinal Cord Inj Rehabil 2009; 14: 122-132.

10 Martin Ginis KA, Arbour-Nicitopoulos KP, Latimer AE, Buchholz AC, Bray SR, Craven $\mathrm{BC}$ et al. Leisure time physical activity in a population-based sample of people with spinal cord injury part II: activity types, intensities, and durations. Arch Phys Med Rehabil 2010; 91: 729-733.

11 Roberton T, Bucks RS, Skinner TC, Allison GT, Dunlop SA. Barriers to physical activity in individuals with spinal cord injury: a western Australian study. Rehabili Counsell 2011; 17: 74-88.

12 Kahn EB, Ramsey LT, Brownson RC, Heath GW, Howze EH, Powell KE et al. The effectiveness of interventions to increase physical activity: a systematic review. Am J Prev Med 2002; 22: 73-107.

13 Kirshblum SC, Burns SP, Biering-Sorensen F, Donovan W, Graves DE, Jha A et al. International standards for neurological classification of spinal cord injury (revised 2011). J Spinal Cord Med 2011; 34: 535-546.

14 Latimer AE, Martin Ginis KA, Craven BC, Hicks AL. The physical activity recall assessment for people with spinal cord injury: validity. Med Sci Sports Exerc 2006; 38: 208-216.
15 Stratford P, Gill C, Westaway M, Binkley J. Assessing disability and change on individual patients: a report of a Patient Specific Measure. Physiother Can 1995; 47: 258-263.

16 Robins RW, Hendin HM, Trzesniewski KH. Measuring global self-esteem: construct validation of a single-item measure and the Rosenberg self-esteem scale. Pers Soc Psychol Bull 2001; 27: 151-161.

17 World Health Organization. Development of the World Health Organization WHOQOLBREF quality of Life assessment. Psychol Med 1998; 28: 551-558.

18 Haskell WL, Lee IM, Pate RR, Powell KE, Blair SN, Franklin BA et al. Physical activity and public health: updated recommendation for adults from the American College of Sports Medicine and the American Heart Association. Med Sci Sports Exerc 2007; 39: 1423-1434.

19 Martin Ginis KA, Hicks AL, Latimer AE, Warburton DE, Bourne C, Ditor DS et al. The development of evidence-informed physical activity guidelines for adults with spinal cord injury. Spinal Cord 2011; 49: 1088-1096.

20 Cripps RA. Spinal Cord Injury Australia 2006-07. Injury research and statistics series number 48. Cat. no. INJCAT 119. Adelaide: AlHW. 2008.

21 Sevick MA, Dunn AL, Morrow MS, Marcus BH, Chen GJ, Blair SN. Cost-effectiveness of lifestyle and structured exercise interventions in sedentary adults: results of project ACTIVE. Am J Prev Med 2000; 19: 1-8.

22 Rauch A, Fekete C, Cieza A, Geyh S, Meyer T. Participation in physical activity in persons with spinal cord injury: a comprehensive perspective and insights into gender differences. Disabil Health J 2013; 6: 165-176.

23 Griffiths HC, Clinpsy D, Kennedy P. Continuing with life as normal: positive psychological outcomes following spinal cord injury. Top Spinal Cord Inj Rehabil 2012; 18: 241-252.

Supplementary Information accompanies this paper on the Spinal Cord website (http://www.nature.com/sc) 